\title{
3 Research Square

\section{Factors Associated with Alcohol Consumption Among Youth Men, Ethiopian 2016 Demographic Health Survey.}

Kindie Mekuria Tegegne ( $\square$ kindiemekuria@gmail.com )

woldia university https://orcid.org/0000-0003-4505-1285

Biruk Beletew Abate

woldia university

Mesfine Wudu Kassaw

woldia University

Etsay Hailu G/mariam

Aksum University

Mohammed Ahmed Yimam

Woldia University

Research article

Keywords: Alcohol Consumption, Youth men, Ethiopia

Posted Date: December 8th, 2020

DOI: https://doi.org/10.21203/rs.3.rs-122508/v1

License: (c) (1) This work is licensed under a Creative Commons Attribution 4.0 International License.

Read Full License 


\section{Abstract}

Background: Alcohol consumption is a global issue, both developed and underdeveloped countries' health trouble. Specifically in Ethiopia, youth men 15-24 years of age are engaged in psychoactive substances mainly alcohols. Alcoholic person has other concomitant mental illness the discord of school, unemployment and being low socio-economic status.

Methods: A cross-sectional study using the 2016 Ethiopia Demographic and Health Survey (EDHS) data set was applied. The samples were selected using a two-stage stratified cluster sampling technique. The data were analyzed with SPSS version 20. Multivariate logistic regression analysis was performed to identify factors associated with alcohol consumption by controlling confounders. An adjusted odds ratio with a $95 \%$ confidence interval was considered to declare a statistically significant association.

Results: The present study comprised of 4486 weight samples of youth men. The prevalence of alcohol consumption among youth men in this study was $39.3 \%$. Men aged 15-19 (AOR=1.27 (95\% Cl $=1.01$ 1.60), being unemployed ( $\mathrm{AOR}=1.62(95 \% \mathrm{Cl}=1.27-2.07)$, don't have awareness about HIV/AIDS $(A O R=4.70(95 \%=2.44-9.01)$,being married (AOD 0.58(0.39-0.85) and poorer youth men (AOD $=1.75(95 \% \mathrm{Cl}=1.21-2.54)$, being orthodox $(A O R=5.12(95 \% \mathrm{Cl}=2.47-10.64)$, protestant $(\mathrm{AOR}=0.42(95 \% \mathrm{Cl}$ $=0.20-0.87)$ Muslim $(A O R=0.07(95 \% \mathrm{Cl}=0.03-0.16)$ religious followers were significantly associated with alcohol consumption.

Conclusion: Alcohol consumption among youth men was relatively high when we compared with other countries study. Strengthening the awareness of HIV/AIDS, change alcohol drinking experience on religious ceremonies especially in orthodox, organizes the youth and job creation is suggested to avert alcohol consumption trajectory.

\section{Background}

Worldwide, alcohol use causes 1.8 million deaths and $4 \%$ of the total disease burden as measured by the WHO Global Burden of Disease study (1). In 2012, about 5.9\% of all global deaths were attributable to alcohol consumption. There are sex differences in the proportion of global deaths attributable to alcohol $7.6 \%$ males and $4.0 \%$ females (2). Use of substances such as alcohol, khat, and tobacco have long been recognized as one of the leading causes of human suffering and become one of the rising major public health and socio-economic problems worldwide and the use of substances have dramatically increased particularly in developing countries (3-5).

In Ethiopia, alcohol is most frequently used substances which affect public health((5), and (6)). Many young people have more than one behavioral disorder, and present with other diagnosable "co morbidity" disorders (7). An estimated $37 \%$ of alcohol abusers and $53 \%$ of other drug abusers have at least one serious mental illness, and in five individuals with a diagnosable mental illness suffer from a substance abuse disorder(7, 8). 
A study conducted in primary care group practice reviled that patients who have mental disorders have $50.0 \%$ alcohol use disorders and have a disability in social and occupational functioning(9).

Studies showed that alcohol consumption is associated with availability and cost of the substance, psychiatric disorders, social setting, and community attitude peer influence, the paucity of other options for pleasure and diversion, low employment or educational opportunities, being male, age and family history $(5,9-17)$

Substance use among adolescents can lead to cigarette smoking, alcohol drinking, and cannabis use can increase accidental or intentional injuries, a commission of crimes, mood disorders, and mortality $(18,19)$

Understanding the nature and magnitude of substance use as well as the factors that contribute to it should allow the design of effective intervention strategies. However, the pattern and magnitude of factors affecting Psycho Active Substance (PAS) use, especially the use of illicit drugs and NPS among Ethiopian youths, there is limited awareness. Though PAS use has common practices among youths in Ethiopia, few interventions have provided to address the magnitude and associated factors. Moreover, as per the literature review, there is no countrywide data on prevalence and associated factors of alcohol consumption among adolescents'. Thus, the objective of this study was to assess magnitude of alcohol consumption and associated factors among youth men in Ethiopia.

\section{Methods}

The current study uses secondary data from the 2016 Ethiopia Demographic and Health Survey (EDHS). EDHS data were collected from January 18,2016 , to June 27,2016 . In brief, the sampling frame used for the 2016 EDHS is the Ethiopia Population and Housing Census (PHC), which was conducted in 2007 by the Ethiopia Central Statistical Agency(20). The samples for the 2016 EDHS were collected using a stratified cluster sampling design and were selected in two stages. In the first stage, enumeration areas (EA) were selected with probability proportional to the EA size and with independent selection in each sampling stratum. In the second stage, 28 households per cluster were selected with an equal probability of systematic selection. All men age 15-24 who were either permanent residents of the selected households or visitors who stayed in the household the night before the survey were eligible to be interviewed. A total of 12,526 men aged 15-59 participated in the survey. The analytic sample for the current study consisted of men aged $15-24$ years $(n=4486)$.

\section{Study Variables}

The main outcome of interest was the self-reported history of alcohol consumption (yes/no). Men who responded to the question were considered to have engaged in alcohol consumption.

Independent variables were selected based on literature review on factors associated with alcohol consumption and include age, religion, education, and wealth index, type of residence, Khat use, and 
HIV/AIDS information, tobacco use, employment status.

\section{Statistical Analysis}

The data were analyzed using SPSS version 20. Frequencies and weighted percentage of study variables were calculated. Chi-square test was used to examine relationships between alcohol consumption and each of the independent variables was used. Multivariable logistic regression analysis was conducted to control confounders and to identify the factors associated with alcohol consumption. Significantly associated independent variables were entered in the multivariable regression model concerning $p$-values in the statistical significance in the bivariate analysis. An adjusted odds ratio with $95 \%$ confidence interval plus p-values was considered to declare a statistically significant association. As recommended, all statistical procedures incorporated sample weighting as complex sampling design was applied in the 2016 EDHS.

\section{Result}

Among the 2016 EDHS participants, subsamples of 4486 men with ages ranging from 15-24 were incorporated. Of the respondents, 2529 were less than 20 years old, and the median age was 19.09 with a standard deviation of 2.84. Eighty-one percent of the respondents didn't chew chat ever. Around 70 percent of the participants were rural residents; beyond ninety-five percent of study subjects heard about HIV/AIDS. Around 43 percent of the participants were orthodox religious followers (Table 1). 
Table 1

Study participants profile from further analysis of EDHS, 2016

\begin{tabular}{|c|c|c|c|c|c|}
\hline \multirow[t]{2}{*}{ Variables } & \multirow[t]{2}{*}{ Category } & \multicolumn{3}{|c|}{ Alcohol consumption } & \multirow{2}{*}{$\begin{array}{l}\mathrm{p}- \\
\text { value }\end{array}$} \\
\hline & & Yes; n (\%) & No; n (\%) & Total; (\%) & \\
\hline \multirow[t]{2}{*}{ Age } & $15-19$ & $898(20)$ & 1631(36.4) & $\begin{array}{l}2,529 \\
(59.9)\end{array}$ & \\
\hline & $20-24$ & 866(19.3) & 1091(24.3) & $\begin{array}{l}1,957 \\
(40.1)\end{array}$ & $\begin{array}{l}< \\
0.001\end{array}$ \\
\hline \multirow[t]{2}{*}{ Residence } & Urban & $567(12.6)$ & 797(17.8) & $1,364(30.4)$ & 0.042 \\
\hline & Rural & 1197(26.7) & 1925(42.9) & $3,122(69.6)$ & \\
\hline \multirow[t]{6}{*}{ Religion } & Orthodox & $1726(34)$ & 401(8.9) & $2,127(42.9)$ & $\begin{array}{l}< \\
0.001\end{array}$ \\
\hline & Catholic & $17(0.4)$ & $23(0.5)$ & $40(0.9)$ & 0.169 \\
\hline & Protestant & $113(2.5)$ & $673(15)$ & 786(17.5) & 0.013 \\
\hline & Muslim & $95(2.1)$ & 1592(35.5) & $1,687(37.6)$ & $\begin{array}{l}< \\
0.001\end{array}$ \\
\hline & Traditional & $3(0.1)$ & $6(0.1)$ & $9(0.2)$ & \\
\hline & Others & $10(0.2)$ & $27(0.6)$ & $37(0.8)$ & \\
\hline \multirow[t]{2}{*}{ Ever heard of AIDS } & Yes & 1746(38.9) & $2530(56.4)$ & $4,276(95.3)$ & \multirow{2}{*}{$\begin{array}{l}< \\
0.001\end{array}$} \\
\hline & No & $18(0.4)$ & 192(4.3) & $210(4.7)$ & \\
\hline \multirow{2}{*}{$\begin{array}{l}\text { Had any STI in the last } 12 \\
\text { months }\end{array}$} & Yes & 1497(33.4) & $267(6)$ & 1764(39.4) & \multirow[t]{2}{*}{0.32} \\
\hline & No & $2374(52.9)$ & $348(7.8)$ & $2722(60.7)$ & \\
\hline \multirow[t]{5}{*}{ Wealth index } & Poorest & $718(16)$ & 261(5.8) & $979(21.8)$ & \\
\hline & Poorer & $351(7.8)$ & $257(5.7)$ & $608(13.5)$ & $\begin{array}{l}< \\
0.001\end{array}$ \\
\hline & Middle & $356(7.9)$ & $269(6)$ & $625(13.9)$ & $\begin{array}{l}< \\
0.001\end{array}$ \\
\hline & Rich & $444(9.9)$ & 314(7) & 758(16.9) & $\begin{array}{l}< \\
0.001\end{array}$ \\
\hline & Richer & 853(19) & $663(14.8)$ & 1516(33.8) & $\begin{array}{l}< \\
0.001\end{array}$ \\
\hline \multirow[t]{3}{*}{ Educational level } & No education & 171(3.8) & $333(7.4)$ & $504(11.2)$ & \\
\hline & Primary & $934(20.8)$ & 1545(34.4) & $\begin{array}{l}2,479( \\
55.2)\end{array}$ & 0.112 \\
\hline & Secondary & 442(9.9) & 659(14.7) & $1,101($ & 0.017 \\
\hline
\end{tabular}




\begin{tabular}{|c|c|c|c|c|c|}
\hline & \multicolumn{5}{|c|}{ 24.6) } \\
\hline & Higher & $217(4.8)$ & $185(4.1)$ & 402(8.9) & $\begin{array}{l}< \\
0.001\end{array}$ \\
\hline \multirow[t]{4}{*}{ Current marital status } & Never in union & 1559(34.8) & 2376(53) & $\begin{array}{l}3,935( \\
87.8)\end{array}$ & \\
\hline & Married & 169(3.8) & $315(7)$ & $484(10.8)$ & 0.046 \\
\hline & $\begin{array}{l}\text { Living with a } \\
\text { partner }\end{array}$ & $4(0.1)$ & $13(0.3)$ & $17(0.4)$ & 0.186 \\
\hline & Divorced & $32(0.7)$ & $18(0.4)$ & $50(1.1)$ & $\begin{array}{l}< \\
0.001\end{array}$ \\
\hline \multirow[t]{2}{*}{ Chewed chat } & No & $1529(34.1)$ & 2103(46.9) & $3,632(81)$ & \\
\hline & yes & $235(5.2)$ & 619(13.8) & $854(18.8)$ & $\begin{array}{l}< \\
0.001\end{array}$ \\
\hline \multirow[t]{2}{*}{ Tobacco } & Don't smoke & 1708(38.1) & $2635(58.7)$ & $4,343(96.8)$ & $\begin{array}{l}<.001 \\
0.001\end{array}$ \\
\hline & Smokes & $56(1.2)$ & $87(1.9)$ & 143(3.1) & \\
\hline \multirow[t]{2}{*}{ Sexual experience } & Had sex & $622(13.9)$ & $703(15.7)$ & 1325(29.6) & \\
\hline & Didn't have sex & 1142(25.5) & $2019(45)$ & $3161(70.5)$ & $\begin{array}{l}< \\
0.46\end{array}$ \\
\hline \multirow[t]{2}{*}{ Employment status } & Employed & 1397(31.1) & $1841(41)$ & $3238(72.1)$ & \\
\hline & Unemployed & $367(8.2)$ & $881(19.6)$ & $1248(27.8)$ & $\begin{array}{l}<.001 \\
0.01\end{array}$ \\
\hline
\end{tabular}

\section{The Prevalence Of Alcohol Consumption In Ethiopia}

The overall prevalence of alcohol consumption in this study was $39.3 \%$ (Table 2).

Table 2

prevalence of alcohol consumption among men aged 15-24 years, 2016 EDHS.

\begin{tabular}{|lll|}
\hline Alcohol consumption & Frequency $(\mathbf{N}=4486)$ & Percentage \\
\hline Yes & 1764 & 39.3 \\
No & 2722 & 60.7 \\
\hline
\end{tabular}

Factors associated with alcohol consumption among youth men in Ethiopia

In bivariate logistic regression, men aged 20-24, being orthodox, protestant, muslin, didn't have HIV/AIDS awareness, poorer, middle rich, richer, youth men who were secondary, higher education, married, divorced 
didn't chew chat, and unemployed were significantly associated at $p$-value $<0.05$, while in multivariable logistic regression: men aged 20-24, being orthodox, protestant, muslin, didn't have HIV/AIDS awareness, poorer, married and didn't chew chat and unemployed were significantly associated with respondents of alcohol consumption. Men aged 20-24 (AOR $=1.27(95 \% \mathrm{Cl}=1.01-1.60 ; \mathrm{P}=0.040)$ had higher odds of alcohol consumption compared with men aged 15-19. Being orthodox religious follower $(A O R=$ 5.12 $(95 \% \mathrm{Cl}=2.47-10.64 ; \mathrm{P}<0.001)$, protestant $(\mathrm{AOR}=0.42(95 \% \mathrm{Cl}=0.20-0.87 ; \mathrm{P}=0.021)$, Muslim $(\mathrm{AOR}=0.07(95 \% \mathrm{Cl}=0.03-0.16 ; \mathrm{P}<0.001)$ had higher odds of alcohol consumption compared with traditional followers. The respondent who didn't have HIV/AIDS information (AOR = 4.70(95\% 2.44-9.01; $P<0.001)$ had higher odds of alcohol consumption as compared to have information. Likewise, Poorer $(A O R=1.75(95 \% \mathrm{Cl}=1.21-2.54 ; \mathrm{P}=0.003)$ men had a higher odds of alcohol consumption compared to the poorest.

However, married men $(\mathrm{AOR}=0.58(95 \% \mathrm{Cl}=0.39-0.85 ; \mathrm{P}=0.005)$ and who didn't chew chat $(0.27(0.19-$ 0.38 ) had a lower odds of alcohol consumption compared to never married men and chat chewer, respectively. Unemployed $(\mathrm{AOR}=1.62(95 \% \mathrm{Cl}=1.27-2.07 ; \mathrm{P}<0.001)$ had higher alcohol consumption as compared to employed as depicted in Table 3. 
Table 3

Multivariate analysis of factors associated with alcohol consumption among youth men's in Ethiopia, further analysis of EDHS 2016.

\begin{tabular}{|c|c|c|c|c|}
\hline Covariates & Category & $\operatorname{COR}(95 \% \mathrm{Cl})$ & AOR95\%Cl & P-value \\
\hline \multirow[t]{2}{*}{ Age } & $15-19$ & 1 & 1 & \\
\hline & $20-24$ & $1.44(1.28-1.63)$ & $1.27(1.01-1.60) *$ & $<0.001$ \\
\hline \multirow[t]{2}{*}{ Residence } & Urban & $1.14(1.00-1.30)$ & $0.76(0.50-1.14)$ & 0.181 \\
\hline & Rural & 1 & 1 & \\
\hline \multirow[t]{5}{*}{ Religion } & Orthodox & $9.66(5.04-18.5)$ & $5.12(2.47-10.64)^{\star \star}$ & $<0.001$ \\
\hline & Catholic & $1.88(0.77-4.60)$ & $2.00(0.75-5.31)$ & 0.164 \\
\hline & Protestant & $0.43(0.22-0.84)$ & $0.42(0.20-0.87)$ * & 0.021 \\
\hline & Muslim & $0.15(0.08-0.30)$ & $0.07(0.03-0.16)^{\star \star}$ & $<0.001$ \\
\hline & Traditional & 1 & 1 & \\
\hline \multirow[t]{2}{*}{ Awareness of HIV/ AIDS } & Yes & 1 & 1 & \\
\hline & No & 7.36(4.32-11.9) & $4.70(2.44-9.01)^{\star \star}$ & $<0.001$ \\
\hline \multirow[t]{5}{*}{ Wealth Index } & Poorest & 1 & 1 & \\
\hline & Poorer & $2.01(1.63-2.50)$ & $1.75(1.21-2.54)^{\star \star}$ & 0.003 \\
\hline & Middle & $2.08(1.68-2.57)$ & $1.27(0.88-1.83)$ & 0.209 \\
\hline & Richer & $1.95(1.60-2.38)$ & $1.18(0.82-1.68)$ & 0.373 \\
\hline & Richest & $2.14(1.80-2.55)$ & $1.49(0.97-2.30)$ & 0.068 \\
\hline \multirow[t]{4}{*}{ Educational Level } & No Education & 1 & 1 & \\
\hline & Primary & $1.18(0.96-1.44)$ & $0.94(0.64-1.39)$ & 0.768 \\
\hline & Secondary & $1.31(1.05-1.63)$ & $0.94(0.61-1.44)$ & 0.781 \\
\hline & Higher & $2.28(1.75-2.99)$ & $1.59(0.95-2.65)$ & 0.077 \\
\hline \multirow[t]{4}{*}{ Current Marital Status } & Never In Union & 1 & 1 & \\
\hline & Married & $0.82(0.67-0.99)$ & $0.58(0.39-0.85)^{\star \star}$ & 0.005 \\
\hline & Living With Partner & $0.47(0.15-1.44)$ & $0.31(0.71-1.34)$ & 0.117 \\
\hline & Divorced & $2.71(1.52-4.84)$ & $1.36(0.52-3.57)$ & 0.527 \\
\hline Chewed Khat & No & $1.92(1.63-2.26)$ & $0.27(0.19-0.38)^{\star \star}$ & $<0.001$ \\
\hline
\end{tabular}




\begin{tabular}{|c|c|c|c|c|}
\hline & Yes & 1 & 1 & \\
\hline \multirow[t]{2}{*}{ Employment Status } & Employed & 1 & 1 & \\
\hline & Unemployed & $1.82(1.58-2.10)$ & $1.62(1.27-2.07)^{\star \star}$ & $<0.001$ \\
\hline
\end{tabular}

\section{Discussion}

The overall alcohol consumption prevalence among youth men was $39.3 \%$.The present study is higher than studies were done in Ethiopian undergraduate Aksum university students (28.4\%)(11) and research done in Washington(18).In other words, the magnitude of alcohol consumption is consistent with Kenyan nearly conducted studies(21) and Hawassa (40.8\%)(13).

This study also showed that being married, unemployed, being poorer, lack of awareness of HIV AIDS, Orthodox religious follower, age of the respondents (20-24 years of age) are factors correlated with alcohol consumption.

Our study is higher than studies conducted elsewhere $(11,18)$ this might be due to the difference in sample size, lower accessibility of alcohol and being busy of clinical attachment and have better knowledge on the impact of alcohol consumption. However, our study is consistent with that of others studies $(13,21)$. This might be due to all nations and nationalities of Ethiopian are residents of Hawassa and relatively same socio-economic status respectively.

Muslim religious followers are protective to alcohol consumption, the present study is supported by other studies done $(22,23)$, this is due to highly religious learning started at childhood and their different books teach them not to drink and of course, drinking is evil behavior. nevertheless, Orthodox religion is significantly associated with alcohol consumption; this might be because of alcohol is usually used after fasting, holy service and bible and tradition of Christian think that wine is gift from God, even though drunkenness and intoxification are forbidden. Youth men aged 20-24 are increases alcohol consumption; this is experienced for different reasons; for instance, to stay with their friends to share dormitory while schooling is far from home plus peer pressure is a huge burden. Those youth men have no restrictions to consume alcohol and have higher opportunity. Families and relatives who have an alcohol consumption history or alcohol use disorder unable to provide adequate care for their son, they don't know with whom he plays. Being poorer is associated with increased alcohol consumption which is supported with studies done(24). Youth men with a lack of resource experienced low self- esteem, odd behave, feels despair, and feels anxious and depressed. So then to overcome such a psychological problem, they usually consume alcohol. Even though alcohol consumption calms anxiety initially, in the long run, it escalates anxiety and leads to an AUD. Furthermore, poorer alcohol consumers engaged mainly on homemade alcohol with a lower cost. Being married is inversely associated with alcohol consumption which is supported by studies done in $(17,25-27)$. Here are some of the factors, like reduced social relationships with others, reduction 
in disposable income that is associated with forming a new household may also encourage quitting on drinking, and wives attendance. There might be different reasons why unemployed youth men have a positive association with alcohol consumption. Such as, they have enough free time, stress and also economic deficiency. In turn stress may increase unemployment and alcohol consumption. Those who have no awareness of HIV AIDS were more likely to consume alcohol than have awareness, which is correlated with study(28), this might be due to misperception of the consequence of $A C$ and bad health effects.

\section{Strength And Limitation Of The Study}

This study included a relatively huge dataset, which was representative of the general population and examined the impact of some very pertinent determinants of youth's alcohol consumption. Use of secondary data meant that we had no control over the selection of variables, quality of data, and the measurement of indicators. The information in the survey was self-reported, so there might be social desirability bias.

\section{Conclusions}

Youth men with 20-24 years of age, orthodox, protestant and Muslim, didn't have awareness about HIV/AIDS, poorer, married, unemployed, and didn't chew chat were significantly associated with respondents of alcohol consumption. Youth men's alcohol consumption in Ethiopia exposes them to accidents and risky sexual behavior. Strengthening the awareness of HIV/AIDS, change alcohol drinking experience on religious ceremonies especially in orthodox, organizes the youth and job creation is suggested

\section{Abbreviations}

AC: Alcohol consumption; AOR-Adjusted Odds Ratio; COR: Crude Odds Ratio; EDHS: Ethiopia Demographic Health Survey; PAS: Psycho active substances.

\section{Declarations}

Acknowledgment

We are grateful to the USAID-DHS program for providing 2016 Ethiopian Demographic Health Survey.

Consent for publication

Not applicable

Data sharing statement 
We used the USAID-DHS program 2016 Ethiopian demographic and health survey data set. To request the same or different data for another purpose, a new research project request should be submitted to the DHS program here: https://dhsprogram.com/data/Access-Instructions.cfm. The DHS Program will normally review all data requests within $24-48$ hours (during working days) and provide notification if access has been granted, or additional project information is needed before access can be granted. After receiving permission, the researcher can login and select the specific data in the format they prefer.

\section{Funding}

Not applicable.

Ethical approval and consent to participant

This study used publicly available, de-identified data and did not require review by the Woldia University Health Sciences Center Institutional Review Board.

Consent for publication

Not applicable.

Competing interest

The authors declare that they have no competing interests

\section{Author details}

${ }^{1}$ Deptment of Nursing, Woldia University

${ }^{2}$ Department of Nursing, Woldia University

${ }^{2}$ Department of Nursing, Woldia University

${ }^{2}$ Department of public health, Woldia University

${ }^{3}$ Department of Psychiatry, Aksum University

${ }^{1 *}$ Corresponding Author: Kindie Mekuria,: kindiemekuria@gmail.com

\section{References}

1. Organization WH. The world health report 2002: reducing risks, promoting healthy life: World Health Organization; 2002.

2. Organization WH. Global status report on noncommunicable diseases 2014: World Health Organization; 2014. 
3. Odejide A. Status of drug use/abuse in Africa: A review. International journal of mental health addiction. 2006;4(2):87-102.

4. Organization WH. Global status report on alcohol and health. Geneva: WHO; 2011. Available from: apps who int/iris/bitstream/10665/112736/1/9789240692763\$4eng pdf. 2013:392.

5. Deressa W, Azazh A. Substance use and its predictors among undergraduate medical students of Addis Ababa University in Ethiopia. BMC Public Health. 2011;11(1):660.

6. Fekadu A, Alem A, Hanlon C. Alcohol and drug abuse in Ethiopia: past, present and future. Afr J Drug Alcohol Stud. 2007;6(1):40-53.

7. Compton MT. Clinical manual of prevention in mental health: American Psychiatric Pub; 2009.

8. O'Connell ME, Boat T, Warner KE. Preventing mental, emotional, and behavioral disorders among young people: Progress and possibilities. Washington, DC: National Academies Press; 2009.

9. Weissman MM, Broadhead WE, Olfson M, Sheehan DV, Hoven C, Conolly P, et al. A diagnostic aid for detecting (DSM-IV) mental disorders in primary care. Gen Hosp Psychiatry. 1998;20(1):1-11.

10. Alwan H, Viswanathan B, Rousson V, Paccaud F, Bovet P. Association between substance use and psychosocial characteristics among adolescents of the Seychelles. BMC Pediatr. 2011;11(1):85.

11. Gebreslassie M, Feleke A, Melese T. Psychoactive substances use and associated factors among Axum University students, Axum Town, North Ethiopia. BMC Public Health. 2013;13(1):693.

12. Horner P, Grogan-Kaylor A, Delva J, Bares CB, Andrade F, Castillo M. The association of family and peer factors with tobacco, alcohol, and marijuana use among Chilean adolescents in neighborhood context. Substance abuse rehabilitation. 2011;2:163.

13. Kassa A, Taddesse F, Yilma A. Prevalence and factors determining psychoactive substance (PAS) use among Hawassa University (HU) undergraduate students, Hawassa Ethiopia. BMC Public Health. 2014;14(1):1044.

14. Kebede Y. Cigarette smoking and Khat chewing among college students in North West Ethiopia. Ethiopian Journal of Health Development. 2002;16(1):9-17.

15. Kebede Y, Abula T, Ayele B, Feleke A, Degu G, Kifle A. Substance Abuse (For the Ethiopian Health Center Team: Ethiopian Public Health Training Initiative). 2005.

16. Mossie A. The prevalence and Socio-demographic characteristics of Khat chewing in Jimma town, south western Ethiopia. Ethiopian journal of health sciences. 2002;12(2).

17. Tsegay G, Esmael A. Psychoactive substances use (khat, alcohol and tobacco) and associated factors among Debre Markos University Students, North-West Ethiopia, 2013. J Def Manag. 2014;4(1):1000118.

18. Hawkins JD, Catalano RF, Miller JY. Risk and protective factors for alcohol and other drug problems in adolescence and early adulthood: implications for substance abuse prevention. Psychological bulletin. 1992;112(1):64.

19. Windle M, Windle RC. Depressive symptoms and cigarette smoking among middle adolescents: Prospective associations and intrapersonal and interpersonal influences. J Consult Clin Psychol. 
2001;69(2):215

20. Demographic CE. Health Survey-2011. Central Statistical Agency Addis Ababa. Ethiopia ICF International Calverton, Maryland, USA. 2012. 2016.

21. Okwarah PO. Prevalence and correlates of alcohol use among underage high-school students in Murang'a and Kajiado Counties. Kenya: COHES-JKUAT; 2017.

22. Mullen K, Williams R, Hunt K. Irish descent, religion, and alcohol and tobacco use. Addiction. 1996;91(2):243-54.

23. Assanangkornchai S, Conigrave KM, Saunders JB. Religious beliefs and practice, and alcohol use in Thai men. Alcohol Alcohol. 2002;37(2):193-7.

24. Khan S, Murray RP, Barnes GE. A structural equation model of the effect of poverty and unemployment on alcohol abuse. Addictive behaviors. 2002;27(3):405-23.

25. Mirand AL, Welte JW. Alcohol consumption among the elderly in a general population, Erie County, New York. American journal of public health. 1996;86(7):978 - 84.

26. Prescott CA, Kendler KS. Associations between marital status and alcohol consumption in a longitudinal study of female twins. J Stud Alcohol. 2001;62(5):589-604.

27. Merline AC, O'Malley PM, Schulenberg JE, Bachman JG, Johnston LD. Substance use among adults 35 years of age: prevalence, adulthood predictors, and impact of adolescent substance use. American journal of public health. 2004;94(1):96-102.

28. Vagenas P, Ludford KT, Gonzales P, Peinado J, Cabezas C, Gonzales F, et al. Being unaware of being HIV-infected is associated with alcohol use disorders and high-risk sexual behaviors among men who have sex with men in Peru. AIDS Behav. 2014;18(1):120-7. 